\title{
EphA4 is a prognostic factor in gastric cancer
}

\author{
Kohji Miyazaki ${ }^{1}$, Mikito Inokuchi ${ }^{1 *}$, Yoko Takagi ${ }^{2}$, Keiji Kato ${ }^{1}$, Kazuyuki Kojima ${ }^{3}$ and Kenichi Sugihara ${ }^{1}$
}

\begin{abstract}
Background: Erythropoietin-producing hepatocellular (Eph) receptor, consisting of a family of receptor tyrosine kinases, plays critical roles in tumour development and is considered an attractive target for cancer therapy.

Methods: Tumour samples were obtained from 222 patients with gastric adenocarcinoma who underwent gastrectomy. The expressions of EphA2, EphA4, and ephrinA1 were evaluated immunohistochemically.

Results: High expressions of EphA2, EphA4, and ephrinA1 significantly correlated with variables related to tumour progression, including the depth of invasion, metastatic lymph nodes, pathological stage, and distant metastasis or recurrent disease. High expressions of EphA2, EphA4, and ephrinA1 were significantly associated with poorer disease-specific survival (DSS; $p<0.001, p<0.001, p=0.026$ ). On multivariate analysis, EphA4 was an independent prognostic factor of DSS (hazard ratio [HR], 2.3; 95\% confidence interval [CI], 1.1-4.8; $p=0.028$ ), and EphA2 tended to be a prognostic factor $(\mathrm{HR}, 2.4 ; 95 \% \mathrm{Cl}, 1.0-5.8 ; \mathrm{p}=0.050)$. In stage II and III cancer, EphA4 and EphA2 were both significantly associated with shorter survival ( $p=0.007$ and 0.019$)$, but only EphA2 was an independent prognostic factor (HR, 2.6; 95\% Cl, 1.1-6.3; $\mathrm{p}=0.039)$.
\end{abstract}

Conclusion: EphA4 may play important roles in tumor progression and outcomes in patients with gastric cancer.

Keywords: EphA4, EphA2, ephrinA1, Gastric cancer

\section{Background}

Gastric cancer is the fourth most common malignancy and the second leading cause of death in the world [1]. The outcomes of gastric cancer remain poor, with an estimated relative 5-year survival rate of $25 \%$ in Europe [2]. At present, the treatment of choice for gastric cancer is complete surgical removal of the tumour and adjacent lymph nodes. However, even after macroscopic complete removal of the primary tumour and metastatic lymph nodes, many patients with advanced disease have recurrence. The effectiveness of therapeutic approaches such as chemotherapy, hormonal therapy, and radiotherapy remains very limited. Although combination chemotherapy regimens consisting of two or three cytotoxic agents have been developed, overall survival is 10 to 13 months in patients with unresectable or metastatic gastric cancer who receive chemotherapy [3,4]. Many receptor tyrosine kinases (RTKs) have been shown to be related to tumour progression and patient outcomes in various cancers. RTK inhibitors such as human epidermal growth factor

\footnotetext{
* Correspondence: m-inokuchi.srg2@tmd.ac.jp

${ }^{1}$ Department of Surgical Oncology, Tokyo Medical and Dental University,

1-5-45, Yushima, Bunkyo-ku, Tokyo 113-8519, Japan

Full list of author information is available at the end of the article
}

receptor (HER) have been evaluated, and some have been used to treat gastrointestinal cancers. Only trastuzumab, a monoclonal antibody against the p185HER2 protein, is now used clinically to treat unresectable or metastatic gastric cancers with HER2 overexpression. However, only $12 \%$ of patients with far advanced gastric cancer respond to trastuzumab, and the median survival time was only 16 months in patients with HER2-positive tumours who received chemotherapy with trastuzumab [5]. Other molecules associated with patient survival have therefore been investigated to identify potential targets for chemotherapy.

Erythropoietin-producing hepatocellular (Eph) receptors represent the largest known family of RTKs and are activated by interacting with cell-surface ligands, termed ephrins. Eph receptors are classified into A-type (EphA1-8 and EphA10) and B-type (EphB1-4 and EphB6) according to their interactions with ephrin ligands, which are also classified into A-type and B-type [6]. Eph receptors and ephrin ligands control cell morphology, adhesion, migration, and invasion by modifying the organization of the actin cytoskeleton and influencing the activities of integrins and intercellular adhesion molecules [7]. Combinations of Eph receptors and ephrin ligands are thought to occur in a tissue-type or cancer-type specific manner. In malignant
Ciomed Central

(c) 2013 Miyazaki et al.; licensee BioMed Central Ltd. This is an Open Access article distributed under the terms of the Creative Commons Attribution License (http://creativecommons.org/licenses/by/2.0), which permits unrestricted use, distribution, and reproduction in any medium, provided the original work is properly cited. 
tumours, Eph and ephrin can promote progression by activating downstream signaling pathways. The up-regulation of Eph and ephrin has been reported in various types of cancer. Altered expression patterns of Eph and ephrin correlate with tumour-promoting features such vascularization and epithelial-mesenchymal transition [8]. In gastric cancer, overexpression of EphA2, A4, and ephrinA1 has been reported by a few small studies $[9,10]$. We therefore examined the relation between clinical outcomes and immunohistochemical expression of EphA2, EphA4, and ephrinA1 in gastric cancer.

\section{Methods}

\section{Patients}

The study group comprised 222 patients with primary gastric adenocarcinomas who underwent surgery from
January 2003 through December 2007 at the Department of Esophagogastric Surgery, Tokyo Medical and Dental University. This study was conducted in accordance with the Declaration of Helsinki [11] and approved by the Institutional Review Board of Tokyo Medical and Dental University. Written Informed consent was obtained from all patients in this study. Each tumour was classified according to the tumour-node-metastasis (TNM) system recommended by the International Union against Cancer. Of the 222 patients, 168 were male and 54 were female. The mean age was 64.6 years (range: $21-92$ years). All patients were evaluated for recurrent disease by tumour-marker analysis or diagnostic imaging (computed tomography, ultrasonography, magnetic resonance imaging, and endoscopy) every 3 to 6 months. Patients with distant metastatic or recurrent disease received
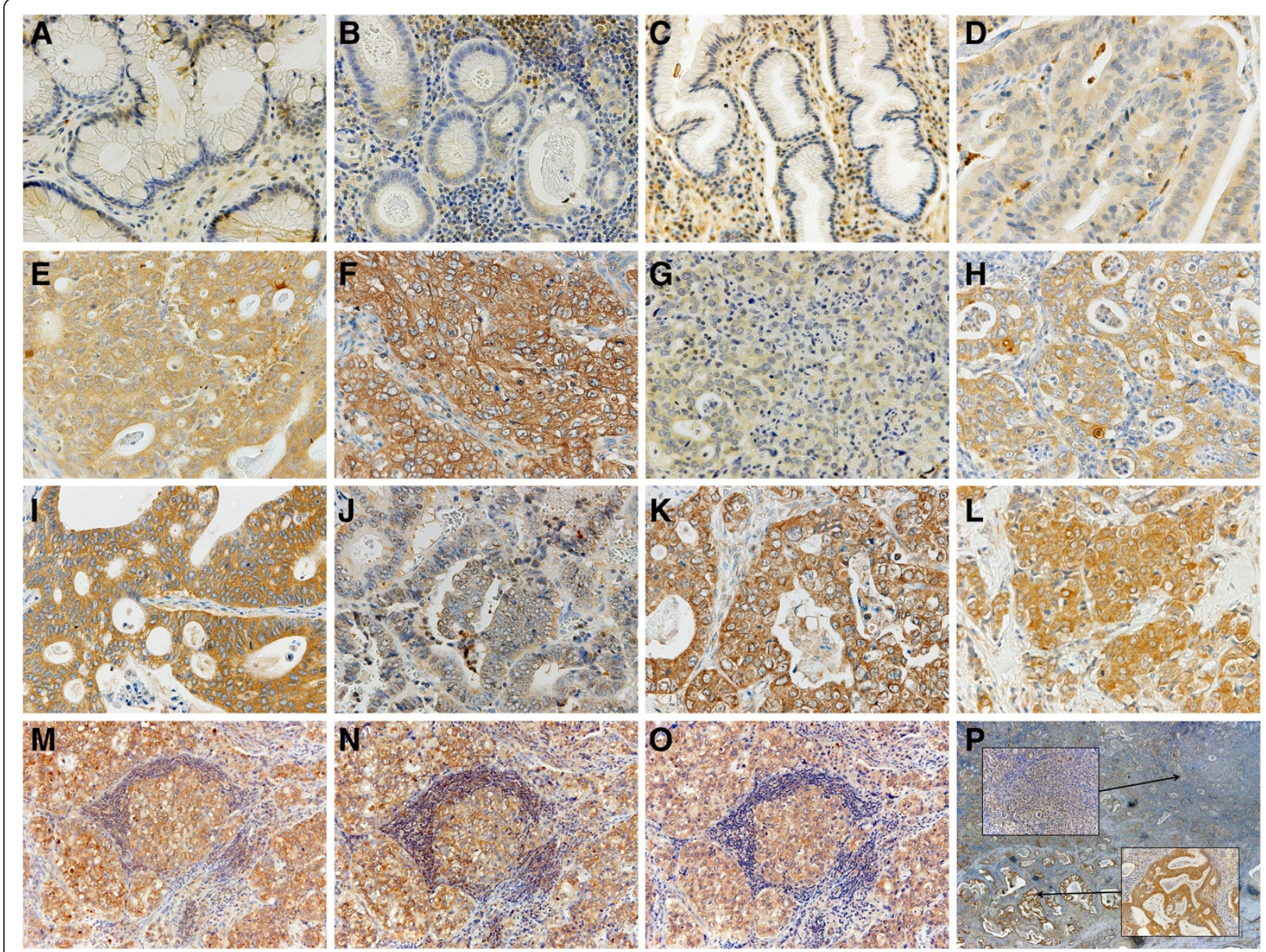

Figure 1 Immunostaining for EphA2, EphA4, and ephrinA1. Representative normal gastric epithelium and stromal cells showing no or weak immunostaining for EphA2 (A), EphA4 (B), and ephrinA1 (C). Representative primary gastric carcinomas showing immunostaining for EphA2 with intensity scores of $1(\mathbf{D}), 2(\mathbf{E})$, and $3(\mathbf{F})$, immunostaining for EphA4 with intensity scores of 1 (G), $2(\mathbf{H})$, and 3 (I), and immunostaining for ephrinA1 with intensity scores of $0(\mathbf{J})$ and $3(\mathbf{K})$. Positive control for ephrinA1 in breast cancer tissue is shown (L). Representative metastatic lymph nodes showing immunostaining for EphA2 (M), EphA4 (N), and ephrinA1 (0). Magnification, 400× (A-L), 200× (M-O), Heterogeneous staining of EphA4 in one tumor (P); magnification, 20x. The upper and lower insets show EphA4 with intensity scores of 1 and 3, respectively; magnification, $200 \times$. 
chemotherapy with S-1 alone or combined chemotherapy. Twenty patients (9\%) received adjuvant chemotherapy with S-1 after radical resection. All patients were followed up until July 2012. The median follow-up was 60 months (3-111). A total of 77 (35\%) patients died, 66 (30\%) had recurrent disease, and 11 (5\%) died of other causes.

\section{Immunohistochemical analysis of EphA2, EphA4, and ephrinA1 proteins}

For immunohistochemical analysis, immunostaining was carried out with the use of a peroxidase-labeled polymer conjugated to secondary antibodies (Histofine Simple Stain MAX PO [MULTI], Nichirei Co., Tokyo, Japan). Polyclonal rabbit antibodies against Eph A2 (C-20, sc924), Eph A4 (S-20, sc-921), and ephrin-A1 (V-18, sc911) were purchased from Santa Cruz Biotechnology, Inc. (Santa Cruz, CA, U.S.A.). These antibodies have been used in other studies [9,12-14], and the specificities of EphA2 and ephrinA1 antibodies were demonstrated by immunoadsorption tests or Western blotting (excluding EphA4) [13,14]. All available hematoxylin-and-eosinstained slides of the surgical specimens were reviewed.

For each case, representative paraffin blocks were selected for immunohistochemical studies. Threemicrometer-thick sections were cut from formalin-fixed, paraffin-embedded tissue blocks. After deparaffinization and rehydration, antigen retrieval treatment was carried out at $98^{\circ} \mathrm{C}$ (microwave processor, MI-77, AZUMAYA, Tokyo, Japan) for $20 \mathrm{~min}$ in $\mathrm{pH}$ 6.0, $10 \mathrm{mmol} / \mathrm{L}$ sodium citrate buffer (Mitsubishi Chemical Medience Corporation, Tokyo, Japan). Endogenous peroxidase was blocked with 3\% hydrogen peroxide in methanol. Nonspecific binding was then blocked by treating the slides with $10 \%$ normal goat serum for $10 \mathrm{~min}$ at room temperature. The slides were incubated with primary antibodies including Eph A2 (dilution 1:100), Eph A4 (1:150), and ephrinA1 (1:200) in 1\% BSA/PBS(-) overnight at $4^{\circ} \mathrm{C}$. Sections were incubated with Simple Stain Max PO (MULTI) for $30 \mathrm{~min}$. After three additional washes, 3,3'-diaminobenzidine tetrahydrochloride solution (Histofine Simple Stain DAB Solution, Nichirei Co.,

Table 1 Correlations among expressions of EphA2, EphA4, and ephrinA1

\begin{tabular}{|c|c|c|c|c|c|c|}
\hline & \multicolumn{2}{|c|}{ EphA4 } & \multirow[b]{2}{*}{$p$} & \multicolumn{2}{|c|}{ ephrinA1 } & \multirow[b]{2}{*}{$p$} \\
\hline & low & high & & low & high & \\
\hline \multicolumn{7}{|l|}{ EphA2 } \\
\hline low & 59 & 18 & \multirow{2}{*}{$<0.001$} & 53 & 24 & \multirow[t]{2}{*}{$<0.001$} \\
\hline high & 52 & 93 & & 54 & 91 & \\
\hline \multicolumn{7}{|l|}{ EphA4 } \\
\hline low & & & & 76 & 35 & \multirow[t]{2}{*}{$<0.001$} \\
\hline high & & & & 31 & 80 & \\
\hline
\end{tabular}

Tokyo, Japan) was applied. Sections were then counterstained with Mayer's hematoxylin (WAKO, Tokyo, Japan). Negative controls were treated similarly, except that the antibodies were replaced by normal rabbit IgG (Santa Cruz Biotechnology, Inc.). Breast cancer tissues served as positive controls.

\section{Interpretation of the immunostaining results}

Staining intensity was scored into four grades: 0 (none), 1 (weakly positive), 2 (moderately positive), and 3 (strongly positive). Staining extent (positive frequency) was also scored into four grades according to the percentage of stained tumour cells: 0 for complete absence of staining, 1 for $<20 \%, 2$ for $20 \%$ to $<50 \%$, and 3 for $\geq 50 \%$ cells. Composite scores were derived by multiplying the intensity score by the staining-extent score. For statistical analysis, composite scores of $\geq 4$ were defined as high expression, and scores of $<4$ were considered low expression. Two investigators (M.K. and T.Y.), who were blinded to patients' outcomes separately counted stained cancer cells in at least three fields per section, including the deepest site invaded by cancer cells, the surface of the lesion, and an intermediate zone. Any disagreements between the two investigators were resolved by reassessment and consensus.

\section{Statistical analysis}

The $\chi^{2}$ test was used to test possible associations of Eph/ ephrin expression with clinicopathological variables. The Mann-Whitney $U$-test was used to analyse the relation between Eph/ephrin expression and patient age. KaplanMeier curves were plotted to assess the effect of Eph/ ephrin expression on disease-specific survival (DSS). Different DSS curves were compared using the log-rank test. Multivariate proportional Cox models were used to assess the prognostic significance of Eph/ephrin and factors associated with DSS. $P$ values of less than 0.05 were considered to indicate statistical significance. Statistical

Table 2 Correlations of EphA2, EphA4, and ephrinA1 between primary tumour and metastatic lymph nodes

\begin{tabular}{ccccc}
\hline & & \multicolumn{3}{c}{ Metastatic lymph nodes } \\
\cline { 3 - 5 } & EphA2 & low & high & p \\
\hline \multirow{4}{*}{ low } & 8 & 12 & 0.87 \\
high & 27 & 44 & \\
Primary & EphA4 & & & \\
tumor & low & 14 & 12 & 0.012 \\
& high & 17 & 48 & \\
& ephrinA1 & & & \\
& low & 21 & 15 & 0.85 \\
& high & 31 & 24 & \\
\hline
\end{tabular}


Table 3 Correlations between the expression of EphA2, EphA4, and ephrinA1 and clinicopathological factors

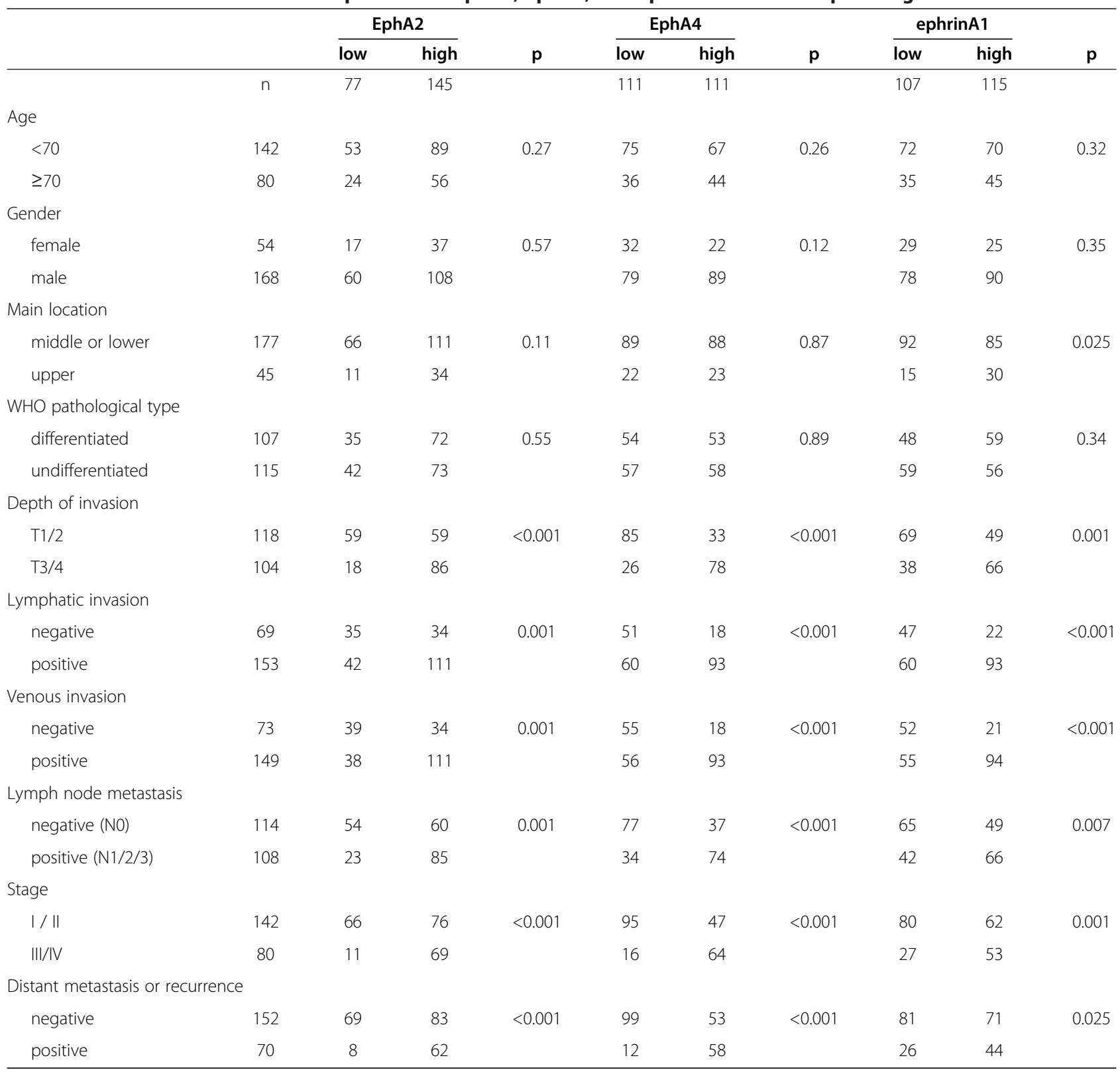

analysis was done using IBM SPSS Statistics 20 software (IBM, Inc., Armonk, NY, U.S.A.).

\section{Results}

Immunohistochemistry of EphA2, EphA4, and ephrinA1 Expressions of EphA2, EphA4, and ephrinA1 were mainly observed in the cytoplasm of cancer cells (Figure 1). Expression was also noted in lymphocytes and blood endothelial cells in cancer tissue. Weak expression was found in some regions of normal epithelium. High expression of EphA2, EphA4, and ephrinA1 was found in 145 (65\%), 111 (50\%), and 115 (52\%) patients, respectively. The numbers of patients with composite scores of 4,5 , and 6 were respectively $56(25 \%), 72(32 \%)$, and 17 (8\%) for EphA2, 8 (26\%), 41 (18\%), and 12 (5\%) for EphA4, and 79 (36\%), 32 (14\%), and 4 (2\%) for ephrinA1. High expression of EphA2, EphA4, or ephrinA1 significantly correlated with high expression of each of the other two proteins (Table 1). On evaluation of 91 metastatic lymph nodes, high expression of EphA2, EphA4, and ephrinA1 was found in 56 (62\%), 60 (66\%), and 39 (43\%) patients, respectively. However, only EphA4 showed a significant relation between expression in primary tumours and that in metastatic lymph nodes $(\mathrm{p}=0.012$, Table 2$)$. 


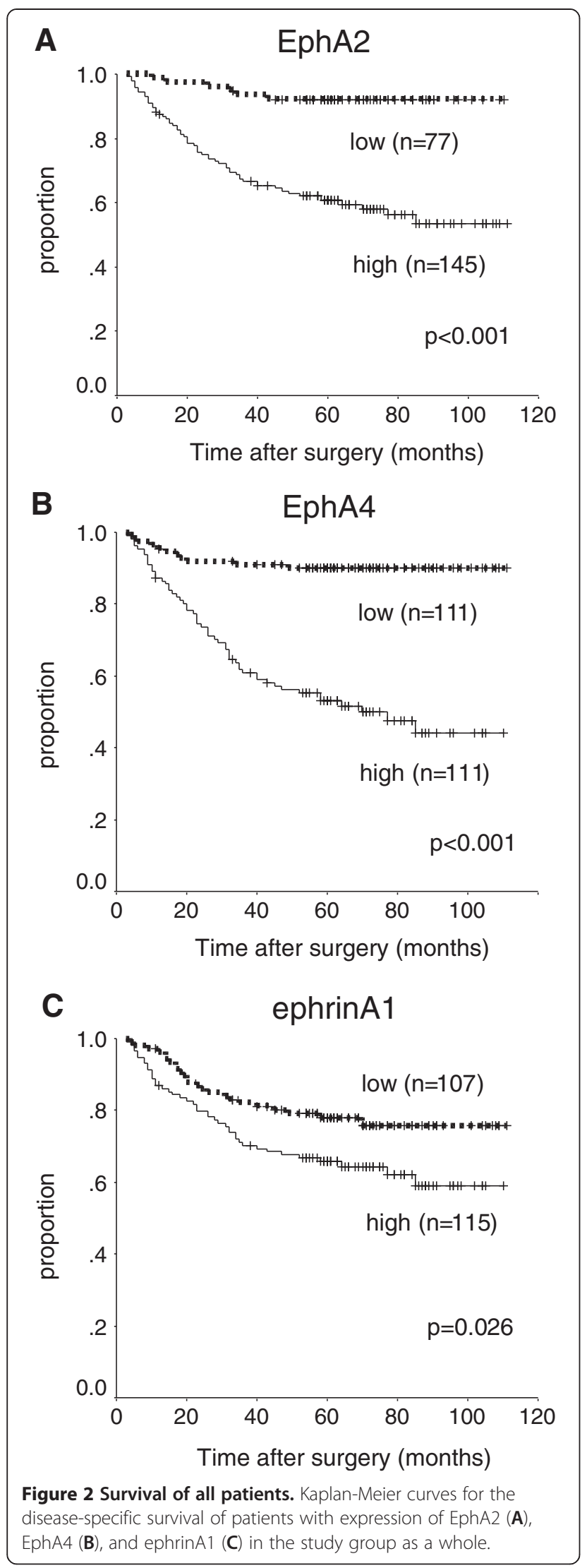

\section{Relationship to clinicopathological variables}

Clinicopathological variables are shown in Table 3. High expressions of EphA2, EphA4, and ephrinA1 were significantly associated with the depth of tumour invasion (T3T4 versus T1-T2; $\mathrm{p}<0.001, \mathrm{p}<0.001$, and $\mathrm{p}=0.001$, respectively), lymph node metastasis $(\mathrm{p}=0.001, \mathrm{p}<0.001$, and $\mathrm{p}=0.007$, respectively), and tumour stage (III-IV versus I-II; $\mathrm{p}<0.001, \mathrm{p}<0.001$, and $\mathrm{p}=0.001$, respectively). Lymphatic and venous invasion were significantly associated with high expressions of EphA2, EphA4, and ephrinA1 (lymphatic invasion: $\mathrm{p}=0.001, \mathrm{p}<0.001$, and $\mathrm{p}<0.001$; venous invasion: $\mathrm{p}<0.001, \mathrm{p}<0.001$, and $\mathrm{p}<0.001$, respectively). Distant metastasis or recurrence was found in a significantly higher proportion of patients with high expressions of EphA2, EphA4, and ephrinA1 than in those with low expressions of these proteins $(p<0.001, p<0.001$, and $\mathrm{p}=0.025$, respectively).

\section{Relationship to DSS}

High expressions of EphA2, EphA4, and ephrinA1 were significantly associated with poorer DSS on univariate analysis $(\mathrm{p}<0.001, \mathrm{p}<0.001$, and $\mathrm{p}=0.026$, respectively, Figure 2 ). The 5 -year DSS was respectively $60 \%, 52 \%$, and $65 \%$ in patients with high expression of EphA2, EphA4, and ephrinA1, as compared with $92 \%, 90 \%$, and $78 \%$ in patients with low expression. EphA4 was an independent predictor of DSS (HR, 2.3; 95\% CI, 1.1-4.8; $\mathrm{p}=0.028$ ) on multivariate Cox proportional-hazards regression analysis (Table 4) adjusted for the following established clinical prognostic factors: depth of tumour (T3-T4 versus T1-T2 ), lymph node metastasis, and histopathological type (undifferentiated versus differentiated). EphA2 showed a trend toward being an independent prognostic factor $(\mathrm{HR}$, $2.4 ; 95 \% \mathrm{CI}, 1.0-5.8 ; \mathrm{p}=0.050$ ).

\section{Relationship to DSS in stage II and III disease}

In patients with pathological stage II and III disease, high expression levels of EphA2 and EphA4 were significantly associated with poorer DSS on univariate analysis $(\mathrm{p}=0.019, \mathrm{p}=0.007$, Figure 3$)$. In contrast, ephrinA1 was unrelated to DSS $(\mathrm{p}=0.39)$. The 5 -year DSS was respectively $52 \%$ and $49 \%$ in patients with high expression of EphA2 and EphA4, as compared with $83 \%$ and $79 \%$ in those with low expression. EphA4 was an independent predictor of DSS on multivariate Cox proportionalhazards regression analysis (HR, 2.6; 95\% CI, 1.1-6.3; $\mathrm{p}=0.039$, Table 5) adjusted for the following established clinical prognostic factors: depth of tumour (T4 versus T1-T3), lymph node metastasis, and histopathological type. The depth of tumour invasion was classified into T4 and T1-3 tumours in this limited population because there were few T1 and T2 tumors, and the difference in DSS was more statistically significant between T4 and T1-3 than that between T3-4 and T1-2 on univariate 
Table 4 Prognostic factors in univariate and multivariate Cox proportional-hazards regression models for diseasespecific survival in the study group as a whole

\begin{tabular}{|c|c|c|c|c|c|}
\hline & \multicolumn{2}{|c|}{ Univariate (Log-rank) } & \multirow[b]{2}{*}{ HR } & \multicolumn{2}{|c|}{ Multivariate } \\
\hline & 5-yr DSS(\%) & $\mathrm{p}$ & & $95 \% \mathrm{Cl}$ & $\mathrm{p}$ \\
\hline \multicolumn{6}{|l|}{ Age } \\
\hline$<70$ & 72 & & & & \\
\hline$\geq 70$ & 69 & 0.37 & & & \\
\hline \multicolumn{6}{|l|}{ Gender } \\
\hline female & 72 & & & & \\
\hline male & 71 & 0.82 & & & \\
\hline \multicolumn{6}{|l|}{ Main location } \\
\hline middle or lower & 74 & & & & \\
\hline upper & 62 & 0.15 & & & \\
\hline \multicolumn{6}{|c|}{ WHO pathological type } \\
\hline differentiated & 80 & & 1 & & \\
\hline undifferentiated & 63 & 0.007 & 1.6 & $0.94-2.7$ & 0.080 \\
\hline \multicolumn{6}{|l|}{ Depth of invasion } \\
\hline $\mathrm{T} 1 / 2$ & 95 & & 1 & & \\
\hline$T 3 / 4$ & 45 & $<0.001$ & 4.2 & $1.6-11$ & 0.003 \\
\hline \multicolumn{6}{|c|}{ Lymph node metastasis } \\
\hline negative & 95 & & 1 & & \\
\hline positive & 47 & $<0.001$ & 4.1 & $1.8-10$ & 0.001 \\
\hline \multicolumn{6}{|l|}{ EphA2 } \\
\hline low & 92 & & 1 & & \\
\hline high & 60 & $<0.001$ & 2.4 & $1.0-5.8$ & 0.050 \\
\hline \multicolumn{6}{|l|}{ EphA4 } \\
\hline low & 90 & & 1 & & \\
\hline high & 52 & $<0.001$ & 2.3 & $1.1-4.8$ & 0.028 \\
\hline \multicolumn{6}{|l|}{ ephrinA1 } \\
\hline low & 78 & & 1 & & \\
\hline high & 65 & 0.026 & 0.88 & $0.50-1.5$ & 0.64 \\
\hline
\end{tabular}

analysis. EphA2 was not a significant prognostic factor in stage II and III gastric cancer.

\section{Discussion}

Our results suggest that high expression of EphA4 and EphA2 may play critical roles in tumor progression, metastasis, and outcomes in gastric cancer. EphA4 was an independent prognostic factor in gastric cancer, even in advanced disease requiring adjuvant chemotherapy after resection to prevent recurrence. Our findings are consistent with those of a previous study showing that overexpression of EphA4 on immunohistochemical analysis is an independent predictor of overall survival in gastric cancer [9]. Overexpression of the EphA4 gene in colorectal primary tumors has been found to be associated with liver metastasis, although expression levels of this gene did not correlate with any other clinicopathological factor and did not differ between cancer tissue and adjacent normal mucosa [10]. In breast cancer, elevated RNA expression of EphA4 had significant prognostic value, as did EphA2, EphA7, and EphB4 [15]. High gene expression of EphA4 has been linked to overexpression of the protein in gastric cancer [9], whereas EphA4 gene amplification has not. Some activated signaling pathways seem to be involved in tumour progression. Activated EphA4 and EphA2 have been shown to trigger the activation of RhoA, which ultimately led to reinitiation of migration in a different direction in a prostate cancer cell line [16]. EphA4 forms a heteroreceptor complex with fibroblast growth factor receptor 1 (FGFR1) in glioma cells, and the EphA4FGFR1 complex potentiates FGFR-mediated downstream signaling [17]. EphA4-ephrinA3 pathway has been considered a promising target in pancreatic cancer cells [12]. EphA4 can interact with Ephrin-A as well as Ephrin-B 


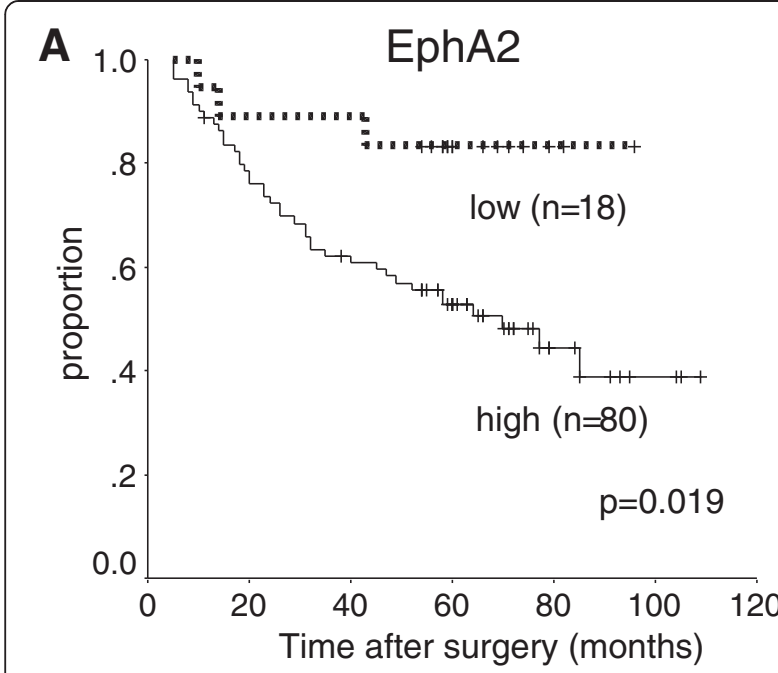

B
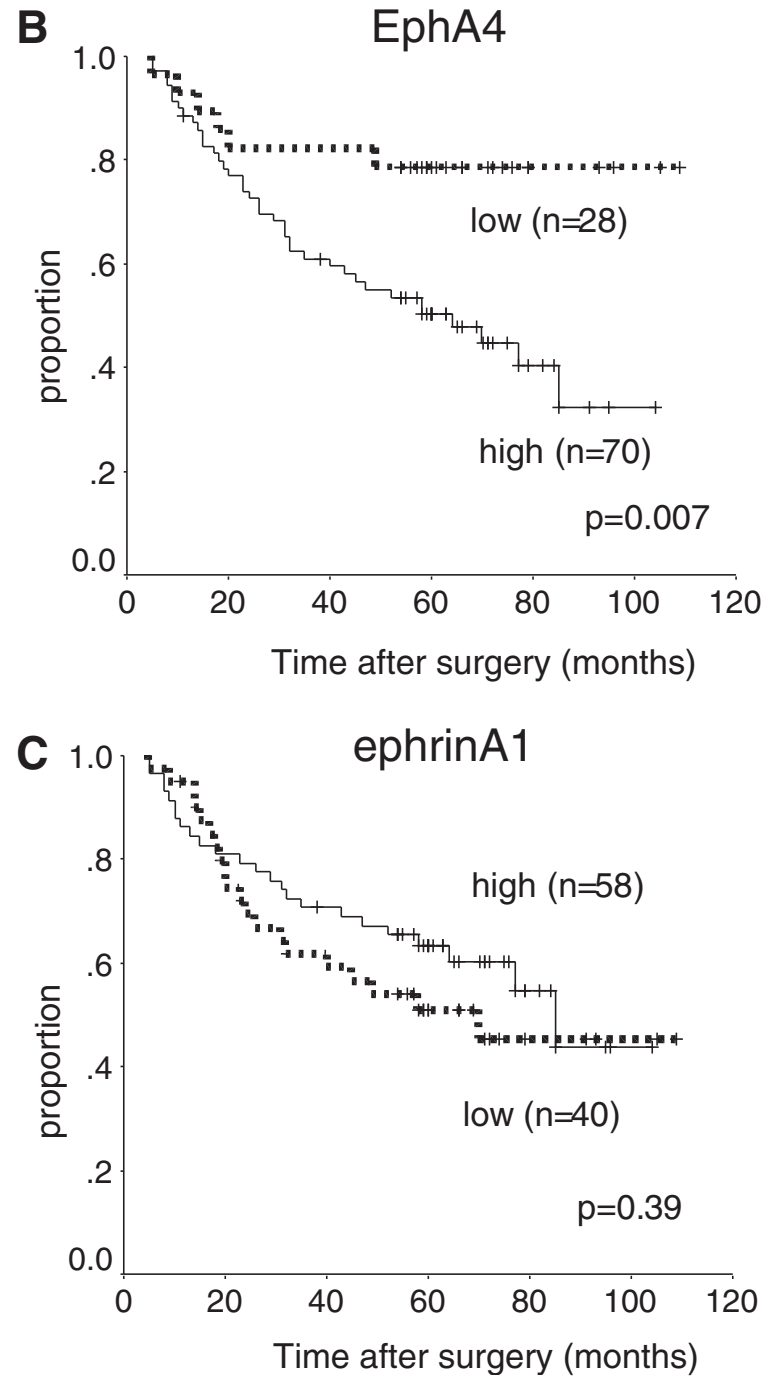

Figure 3 Survival of patients in stage II and III. Kaplan-Meier curves for the disease-specific survival of patients with expression of EphA2 (A), EphA4 (B), and ephrinA1 (C) who had stage II and III disease.
$[18,19]$, although EphA receptors bind mainly to ephrin-A ligands (A1-A5), and EphB receptors bind to transmembrane ephrin-B ligands (B1-B3). In the present study, other ligands for EphA4 (except for ephrinA1) were not investigated. On the other hand, even tumor-suppressive activation of EphA4 was evident in another study. EphA4 has been reported to inhibit downstream Rac, which promotes cell migration, through chimaerin binding to EphA4 in response to ephrinA1 stimulation [20].

EphA2 is thought to down-regulate cell growth and migration in normal epithelium [21]. Interestingly, EphA2 is highly expressed in a variety of cancers, including breast [22], lung [23], prostate [24], urinary bladder [25], ovarian [26], esophageal [27], pancreatic [28], and colorectal cancer [29]. Overexpression of EphA2 is associated with tumour progression or poor patient survival. The expression of ephrinA1, known to be a major ligand of EphA2, has been studied in various cancers. Expressions of both EphA2 and ephrinA1 on the basis of the mRNA level or immunohistochemical analysis have been demonstrated to be higher in gastric cancer than in normal tissue, and EphA2 was significantly associated with poor survival, whereas ephrinA1 was not [13]. EphrinA1 expression has been significantly associated with EphA2 expression, although ephrinA1 was not an independent prognostic factor in several types of cancer $[27,30,31]$. Our findings are in accord with the results of these previous studies. In gastric cancer cell lines that express EphA2, stimulation of EphrinA1 decreases EphA2 protein expression, but increases EphA2 phosphorylation [14]. Also in non-tumour cells, EphA2 was degraded by $\mathrm{Cbl}$ binding to ephrinA1 [32]. On the other hand, expression of EphA2 and ephrinA1 has been confirmed in both the vasculature and tumor cells in cancer tissues, and EphA2 might be required for angiogenesis in an in vitro model [33]. The interaction of Eph receptor and ephrin ligand expressed on vasculature cells might be associated with angiogenesis in tumours. In the present study, EphA2, ephrinA1, and even EphA4 were also expressed in vascular endothelial cells existing in cancer tissue.

Gene expression or quantitative assessment is important and necessary to confirm the outcomes of this study, although mRNA expression levels of EphA2, EphA4, and ephrinA1 were shown to be higher in gastric cancer tissue than in non-cancerous gastric tissue by other investigators $[9,13]$. Many pathological and molecular assays suggest that gastric cancer is a heterogeneous disease. Analysis of one small part of a specimen by techniques such as tissue microarray may not convey the entire picture of heterogeneous diseases such as gastric cancer, consisting of many scattered tumour cells. Staining for EphA2, EphA4, and ephrinA1 often differed between the lesion surface and sites of deep invasive or between differentiated and undifferentiated portions of the same sample in the present study. We also evaluated the expressions of EphA2, EphA4, and 
Table 5 Prognostic factors in univariate and multivariate Cox proportional-hazards regression models for diseasespecific survival in patients with stage II and III disease

\begin{tabular}{|c|c|c|c|c|c|c|}
\hline & \multirow[b]{2}{*}{$\mathbf{n}$} & \multicolumn{2}{|c|}{ Univariate (Log-rank) } & \multirow[b]{2}{*}{ HR } & \multicolumn{2}{|c|}{ Multivariate } \\
\hline & & 5-yr DSS(\%) & $\mathrm{p}$ & & $95 \% \mathrm{Cl}$ & $p$ \\
\hline \multicolumn{7}{|l|}{ Age } \\
\hline$<70$ & 65 & 54 & & & & \\
\hline$\geq 70$ & 33 & 64 & 0.63 & & & \\
\hline \multicolumn{7}{|l|}{ Gender } \\
\hline female & 22 & 64 & & & & \\
\hline male & 76 & 56 & 0.49 & & & \\
\hline \multicolumn{7}{|l|}{ Main location } \\
\hline middle or lower & 78 & 61 & & & & \\
\hline upper & 20 & 44 & 0.24 & & & \\
\hline \multicolumn{7}{|c|}{ WHO pathological type } \\
\hline differentiated & 39 & 69 & & 1 & & \\
\hline undifferentiated & 59 & 50 & 0.077 & 1.7 & $0.86-3.3$ & 0.13 \\
\hline \multicolumn{7}{|l|}{ Depth of invasion } \\
\hline $\mathrm{T} 1-3$ & 48 & 85 & & 1 & & \\
\hline T4 & 50 & 32 & $<0.001$ & 5.5 & $2.5-12$ & $<0.001$ \\
\hline \multicolumn{7}{|c|}{ Lymph node metastasis } \\
\hline negative & 20 & 89 & & 1 & & \\
\hline positive & 78 & 49 & 0.004 & 3.0 & $0.92-9.9$ & 0.070 \\
\hline \multicolumn{7}{|l|}{ EphA2 } \\
\hline low & 18 & 83 & & 1 & & \\
\hline high & 80 & 52 & 0.019 & 1.7 & $0.52-5.7$ & 0.38 \\
\hline \multicolumn{7}{|l|}{ EphA4 } \\
\hline low & 28 & 79 & & 1 & & \\
\hline high & 70 & 49 & 0.007 & 2.6 & $1.1-6.3$ & 0.039 \\
\hline \multicolumn{7}{|l|}{ ephrinA1 } \\
\hline low & 40 & 51 & & & & \\
\hline high & 58 & 62 & 0.39 & & & \\
\hline
\end{tabular}

ephrinA1 in metastatic lymph nodes. To our knowledge, Eph and ephrin in metastatic sites of gastric cancer have not been investigated previously. Expressions of EphA2 and ephrinA1 differed between primary tumor and lymph node metastasis and correlated significantly with the expression of only EphA4. This discrepancy may have been caused by methodological issues, although gene analysis by extraction from metastatic lymph nodes may be difficult owing to the presence of scattered tumour cells in innumerable lymphocytes. Differences in EphA2 or ephrinA1 expression among tumour sites can make chemotherapy against these molecular targets challenging.

Various molecules targeting Eph and ephrin have been developed. A small molecule that inhibits binding of ephrin to EphA2 and EphA4 has been identified [19], and such inhibitors might be effective against advanced or metastatic gastric cancer. Small interfering RNA-mediated inhibition of EphA2 has been reported to retard tumour growth and inhibit metastasis in an in vivo study of pancreatic adenocarcinoma [34]. However, Eph and ephrin are known to have bidirectional signaling in cancer cells. Therefore, EphA2 agonists most likely enhance tumor suppressor signaling pathways and receptor degradation in cancer cells, but promote tumour angiogenesis [8].

\section{Conclusion}

EphA4 plays an important role in tumour progression and clinical outcomes, similar to EphA2, in patients with gastric cancer. EphA4 is an independent prognostic factor in stage II and III gastric cancer, stages that usually require adjuvant chemotherapy. The expression of EphA4 in primary tumours significantly correlated with that in metastatic lymph nodes. EphA4 may be a promising target for monoclonal antibody therapy in patients with gastric cancer. 


\section{Competing interests}

We declare that we have no competing interests.

\section{Authors' contributions}

$\mathrm{KM}, \mathrm{Ml}$, and $\mathrm{KS}$ were responsible for drafting the manuscript. KM, KK, and YT contributed to immunohistochemistry. $\mathrm{Ml}$ and $\mathrm{KK}$ contributed to analysis and interpretation of data. All authors read and approved the final manuscript.

\section{Author details}

${ }^{1}$ Department of Surgical Oncology, Tokyo Medical and Dental University, 1-5-45, Yushima, Bunkyo-ku, Tokyo 113-8519, Japan. ²Department of Translational Oncology, Tokyo Medical and Dental University, 1-5-45, Yushima, Bunkyo-ku, Tokyo 113-8519, Japan. ${ }^{3}$ Department of Minimally Invasive Surgery, Tokyo Medical and Dental University, 1-5-45, Yushima, Bunkyo-ku, Tokyo 113-8519, Japan.

Received: 10 December 2012 Accepted: 29 May 2013 Published: 5 June 2013

\section{Reference}

1. Ferlay J, Shin HR, Bray F, Forman D, Mathers C, Parkin DM: Estimates of worldwide burden of cancer in 2008: GLOBOCAN 2008. Int J Cancer 2010, 127:2893-2917.

2. Catalano V, Labianca R, Beretta GD, Gatta G, de Braud F, Van Cutsem E: Gastric cancer. Crit Rev Oncol Hematol 2009, 71:127-164.

3. Cunningham D, Starling N, Rao S, Iveson T, Nicolson M, Coxon F, Middleton G, Daniel F, Oates J, Norman AR, Upper Gastrointestinal Clinical Studies Group of the National Cancer Research Institute of the United Kingdom: Capecitabine and oxaliplatin for advanced esophagogastriccancer. $N$ Engl J Med 2008, 358:36-46.

4. Koizumi W, Narahara H, Hara T, Takagane A, Akiya T, Takagi M, Miyashita K, Nishizaki T, Kobayashi O, Takiyama W, Toh Y, Nagaie T, Takagi S, Yamamura Y, Yanaoka K, Orita H, Takeuchi M: S-1 plus cisplatin versus S-1 alone for first-line treatment of advanced gastric cancer (SPIRITS trial): a phase III trial. Lancet Oncol 2008, 9:215-221.

5. Bang YJ, Van Cutsem E, Feyereislova A, Chung HC, Shen L, Sawaki A, Lordick F, Ohtsu A, Omuro Y, Satoh T, Aprile G, Kulikov E, Hill J, Lehle M, Rüschoff J, Kang YK: ToGA Trial Investigators.Trastuzumab in combination with chemotherapy versus chemotherapy alone for treatment of HER2-positive advanced gastric or gastro-oesophageal junction cancer (ToGA): a phase 3, open-label, randomised controlled trial. Lancet 2010, 376:687-697.

6. Surawska H, Ma PC, Salgia R: The role of ephrins and Eph receptors in cancer. Cytokine Growth Factor Rev 2004, 15:419-433.

7. Kullander K, Klein R: Mechanisms and functions of Eph and ephrinsignalling. Nat Rev Mol Cell Biol 2002, 3:475-486.

8. Pasquale EB: Eph receptors and ephrins in cancer: bidirectional signalling and beyond. Nat Rev Cancer 2010, 10:165-180.

9. Oki M, Yamamoto H, Taniguchi H, Adachi Y, Imai K, Shinomura Y: Overexpression of the receptor tyrosine kinase EphA4 in human gastric cancers. World J Gastroenterol 2008, 14:5650-5656.

10. Oshima T, Akaike M, Yoshihara K, Shiozawa M, Yamamoto N, Sato T, Akihito N, Nagano Y, Fujii S, Kunisaki C, Wada N, Rino Y, Tanaka K, Masuda M, Imada $\mathrm{T}$ : Overexpression of EphA4 gene and reduced expression of EphB2 gene correlates with liver metastasis in colorectal cancer. Int J Oncol 2008, 33:573-577.

11. World Medical Association: World Medical Association Declaration of Helsinki: Ethical Principales for Medical Research involving Human Subjects. http:// www.wma.net/en/30publications/10policies/b3/17c.pdf.

12. liizumi M, Hosokawa M, Takehara A, Chung S, Nakamura T, Katagiri T, Eguchi $\mathrm{H}$, Ohigashi H, Ishikawa O, Nakamura Y, Nakagawa H: EphA4 receptor, overexpressed in pancreatic ductal adenocarcinoma, promotes cancer cell growth. Cancer Sci 2006, 97:1211-1216.

13. Yuan WJ, Ge J, Chen ZK, Wu SB, Shen H, Yang P, Hu B, Zhang GW, Chen ZH: Over-expression of EphA2 and EphrinA-1 in human gastric adenocarcinoma and its prognostic value for postoperative patients. Dig Dis Sci 2008, 54:2410-2417.

14. Nakamura R, Kataoka H, Sato N, Kanamori M, Ihara M, Igarashi H, Ravshanov S, Wang YJ, Li ZY, Shimamura T, Kobayashi T, Konno H, Shinmura K, Tanaka $\mathrm{M}$, Sugimura H: EPHA2/EFNA1 expression in human gastric cancer. Cancer Sci 2005, 96:42-47.
15. Brantley-Sieders DM, Jiang A, Sarma K, Badu-Nkansah A, Walter DL, Shyr Y, Chen J: Eph/ephrin profiling in human breast cancer reveals significant associations between expression level and clinical outcome. PLOS One 2011, 6:e24426.

16. Wang B: Cancer cells exploit the Eph-ephrin system to promote invasion and metastasis: tales of unwitting partners. Sci Signal 2011, 4:pe28.

17. Fukai J, Yokote H, Yamanaka R, Arao T, Nishio K, Itakura T: EphA4 promotes cell proliferation and migration through a novel EphA4-FGFR1 signaling pathway in the human glioma U251 cell line. Mol Cancer Ther 2008, 7:2768-2778.

18. Sugimura H, Wang JD, Mori H, Tsuboi M, Nagura K, Igarashi H, Tao H, Nakamura R, Natsume H, Kahyo T, Shinmura K, Konno H, Hamaya Y, Kanaoka S, Kataoka H, Zhou XJ: EPH-EPHRIN in human gastrointestinal cancers. World J Gastrointest Oncol 2010, 2:421-428.

19. Noberini R, Koolpe M, Peddibhotla S, Dahl R, Su Y, Cosford ND, Roth GP, Pasquale EB: Small molecules can selectively inhibit ephrin binding to the EphA4 and EphA2 receptors. J Biol Chem 2008, 283:29461-29472.

20. Takeuchi S, Yamaki N, Iwasato T, Negishi M, Katoh H: Beta2-chimaerin binds to EphA receptors and regulates cell migration. FEBS Lett 2009, 583:1237-1242.

21. Kinch MS, Carles-Kinch K: Overexpression and functional alterations of the EphA2 tyrosine kinase in cancer. Clin Exp Metastasis 2003, 20:59-68.

22. Zelinski DP, Zantek ND, Stewart JC, Irizarry AR, Kinch MS: EphA2 overexpression causes tumorigenesis of mammary epithelial cells. Cancer Res 2001, 61:2301-2306.

23. Kinch MS, Moore MB, Harpole DH Jr: Predictive value of the EphA2 receptor tyrosine kinase in lung cancer recurrence and survival. Clin Cancer Res 2003, 9:613-618.

24. Zeng G, Hu Z, Kinch MS, Pan CX, Flockhart DA, Kao C, Gardner TA, Zhang S, Li L, Baldridge LA, Koch MO, Ulbright TM, Eble JN, Cheng L: High-level expression of EphA2 receptor tyrosine kinase in prostatic intraepithelial neoplasia. Am J Pathol 2003, 163:2271-2276.

25. Abraham S, Knapp DW, Cheng L, Snyder PW, Mittal SK, Bangari DS, Kinch M, Wu L, Dhariwal J, Mohammed SI: Expression of EphA2 and Ephrin A-1 in carcinoma of the urinary bladder. Clin Cancer Res 2006, 12:353-360.

26. Thaker PH, Deavers M, Celestino J, Thornton A, Fletcher MS, Landen CN, Kinch MS, Kiener PA, Sood AK: EphA2 expression is associated with aggressive features in ovarian carcinoma. Clin Cancer Res 2004, 10:5145-5150.

27. Xu F, Zhong W, Li J, Shanshen Z, Cui J, Nesland JM, Suo Z: Predictive value of EphA2 and EphrinA-1 expression in oesophageal squamous cell carcinoma. Anticancer Res 2005, 25:2943-2950.

28. Mudali SV, Fu B, Lakkur SS, Luo M, Embuscado EE, lacobuzio-Donahue CA: Patterns of EphA2 protein expression in primary and metastatic pancreatic carcinoma and correlation with genetic status. Clin Exp Metastasis 2006, 23:357-365.

29. Kataoka H, Igarashi H, Kanamori M, Ihara M, Wang JD, Wang YJ, Li ZY, Shimamura T, Kobayashi T, Maruyama K, Nakamura T, Arai H, Kajimura M, Hanai H, Tanaka M, Sugimura H: Correlation of EPHA2 overexpression with high microvessel count in human primary colorectal cancer. Cancer Sci 2004, 95:136-141.

30. Wu D, Suo Z, Kristensen GB, Li S, Troen G, Holm R, Nesland JM: Prognostic value of EphA2 and EphrinA-1 in squamous cell cervical carcinoma. Gynecol Oncol 2004, 94:312-319.

31. Han L, Dong Z, Qiao Y, Kristensen GB, Holm R, Nesland JM, Suo Z: The clinical significance of EphA2 and Ephrin A-1 in epithelial ovarian carcinomas. Gynecol Oncol 2005, 99:278-286.

32. Wang YJ, Ota S, Kataoka H, Kanamori M, Li Z, Band H, Tanaka M, Sugimura $\mathrm{H}$ : Negative regulation of EphA2 receptor by $\mathrm{Cbl}$. Biochem Biophys Res Commun 2002, 296:214-20.

33. Ogawa K, Pasqualini R, Lindberg RA, Kain R, Freeman AL, Pasquale EB: The ephrin-A1 ligand and its receptor, EphA2, are expressed during tumor neovascularization. Oncogene 2000, 19:6043-6052.

34. Duxbury MS, Ito H, Zinner MJ, Ashley SW, Whang EE: EphA2: a determinant of malignant cellular behavior and a potential therapeutic target in pancreatic adenocarcinoma. Oncogene 2004, 23:1448-1456.

\section{doi:10.1186/1472-6890-13-19}

Cite this article as: Miyazaki et al.: EphA4 is a prognostic factor in gastric cancer. BMC Clinical Pathology 2013 13:19. 